\title{
Application of ${ }^{1} \mathrm{H}$ DOSY for Facile Measurement of Polymer Molecular Weights
}

\author{
Weibin Li ${ }^{\ddagger}$, Hoyong Chung ${ }^{\ddagger}$, Christopher Daeffler, Jeremiah A. Johnson ${ }^{\dagger,}{ }^{\star}$, and Robert H. \\ Grubbs* \\ The Arnold and Mabel Beckman Laboratories of Chemical Synthesis, Division of Chemistry and \\ Chemical Engineering, California Institute of Technology, Pasadena, California 91125, United \\ States \\ ${ }^{\dagger}$ Department of Chemistry, Massachusetts Institute of Technology, Cambridge, Massachusetts \\ 02139, USA
}

\begin{abstract}
To address the practical issues of polymer molecular weight determination, the first accurate polymer weight-average molecular weight determination method in diverse living/controlled polymerization via DOSY (diffusion-ordered NMR spectroscopy) is reported. Based on the linear correlation between the logarithm of diffusion coefficient $(\log \mathrm{D})$ and the molecular weights $(\log$ $\mathrm{Mw}$ ), external calibration curves were created to give predictions of molecular weights of narrowly-dispersed polymers. This method was successfully applied to atom transfer radical polymerization (ATRP), reversible addition-fragmentation chain transfer (RAFT), and ringopening metathesis polymerization (ROMP), with weight-average molecular weights given by this method closely correlated to those obtained from GPC measurement.
\end{abstract}

\section{Keywords}

DOSY; diffusion NMR; living polymerization; ATRP; ROMP; RAFT; weight-average molecular weight

\begin{abstract}
The physical properties of polymers are intimately linked to molecular weight (MW). ${ }^{1,2}$ Methods for polymer synthesis are considered "controlled" when they provide polymers with defined MWs and narrow molecular weight distributions (i.e., low polydispersities, PDIs). These key parameters drastically affect the utility of a polymer for a given application. Because synthetic polymers have polydispersity, we speak of their MWs in terms of averages; choice of a relevant average MW is defined by the physical property under consideration. The most common average MWs can be measured via a variety of different techniques such as gel permeation chromatography (GPC, for number-average molecular weight, $\mathrm{Mn}$ ), osmometry (Mn), static light scattering (weight-average molecular weight, $\mathrm{Mw}$ ), matrix-assisted laser desorption-ionization mass spectrometry ( $\mathrm{Mn}$ and $\mathrm{Mw}$ ), viscometry (Mv), field-flow fractionation, small-angle X-ray scattering, small-angle neutron
\end{abstract}

\footnotetext{
*Corresponding Author. Telephone: +1 626395 6003. (R. H. G.) rhg@ @altech.edu. Telephone: +1 617 253-1819. (J. A. J.) jaj2109@mit.edu.

FThese authors contributed equally.

The authors declare no competing financial interest.

ASSOCIATED CONTENT

Supporting Information

NMR spectra and experimental procedures. This information is available free of charge via the Internet at http://pubs.acs.org/.
} 
scattering, ultracentrifugation, cryoscopy, ebulliometry and end-group analysis. ${ }^{3-8}$ The weight-average molecular weight is particularly useful to determine certain bulk properties of polymer materials including mechanical properties, thermal properties, and viscoelastic properties. The most common way to determine $\mathrm{Mw}$ is via static light scattering, which relates the intensity of scattered light to molar mass. LS systems are not routinely available in most synthetic labs; analysis of Mw is typically achieved via comparison of GPC retention times to polymer standards.

Although it is easy to obtain molecular weights and molecular weight distributions by GPC analysis, this characterization has many practical drawbacks. For instance, GPC experiments are often time-consuming (typically $\sim 15 \mathrm{~min}-60 \mathrm{~min}$ per sample), furthermore, GPC instruments often consume large amounts of organic solvent for a single measurement. Also, GPC requires regular calibration to get reliable information without a LS detector. The expensive columns and detectors are additional burden for GPC maintenance. Additionally, potential solubility problems could rise when changing solvents. Lastly, GPC is incapable of yielding accurate $\mathrm{Mw}$ results at low $\mathrm{Mw}$ range $(<2000 \mathrm{~g} / \mathrm{mol})$.

In polymer science, 1-D and 2-D NMR techniques have been widely utilized to characterize number-average molecular weight (Mn), chemical composition, and microstructures of polymers. ${ }^{9,10}$ Although NMR is very powerful in measuring Mn via end-group analysis, this method is limited to low molecular weights and situations where polymer backbone resonances do not overlap with end groups. We reasoned that diffusion-ordered NMR spectroscopy (DOSY), which relates the chemical shifts of NMR resonances from a given molecular species to the translational diffusion coefficient of that species, could offer a facile method for accurate determination of molecular weights.

DOSY has been utilized as a powerful tool in recent years to investigate solution state structures and interactions of small organic molecules, organometallic aggregates, and macromolecules. ${ }^{11-18}$ It provides diffusion coefficients of molecules, which are related to hydrodynamic radius and molecular weights. ${ }^{19-22}$ Johnson invented and applied DOSY to determine polymer weight distribution. ${ }^{14}$ Delsuc reported a DOSY-based method to calculate PDIs of linear polymers. ${ }^{23}$ DOSY was also utilized by Matyjaszewski to evaluate solvent effects in the atom transfer radical polymerization (ATRP). ${ }^{24}$ Our lab has recently utilized DOSY to characterize a molecular charm bracelet prepared via ring-closing metathesis and polyrotaxanes prepared via multicomponent ADMET polymerization. ${ }^{25,26}$

Internal reference systems for ${ }^{1} \mathrm{H},{ }^{31} \mathrm{P}$, and ${ }^{6} \mathrm{Li}$ DOSY have been successfully applied to determine the molecular weights of a panel of air/moisture sensitive organometallic complexes and self-assembly systems. ${ }^{27-35}$ Given appropriate internal references, formula weights of organic compounds can be estimated within $\pm 10 \%$ deviation through diffusion coefficient - molecular weight (D-Mw) analysis, which is based on the linear correlation of the logarithm of diffusion coefficients $(\log \mathrm{D})$ to the logarithm of the molecular weights of the references $(\log \mathrm{Mw}) .{ }^{22,31-35}$ By evaluating the concentration, viscosity and density effects on DOSY measurements respectively, accurate molecular weight information has been obtained when the internal reference solution was physically separated from the analyte solution by means of a glass capillary as an insert into the NMR tubes. ${ }^{32,33}$ This was most easily accomplished when the reference and analyte solution concentrations were at or below $\mu \mathrm{M}$ level, and therefore the solution properties approached those of the pure solvent.

We envisioned that the principles of the aforementioned reference systems for DOSY could be adopted to create external calibration curves for polymer solutions that would allow one to predict weight-average molecular weights of polymers and monitor the kinetics of living 
polymerization. For ${ }^{1} \mathrm{H}$ DOSY, the acquisition time can be as short as 4 minutes and the concentration can be at $\mu \mathrm{M}$ range, which are ideal for polymer measurements.

This report presents the first use of DOSY technology for the determination of Mw values for kinetic samples from various living/controlled polymerization. To demonstrate the generality of this approach, we synthesized model polymers of varied composition via three different controlled polymerization methods: atom transfer radical polymerization (ATRP), ${ }^{36-38}$ reversible addition-fragmentation chain transfer (RAFT), ${ }^{39-42}$ and ringopening metathesis polymerization (ROMP). ${ }^{43-47}$ Kinetic studies were performed on model polymerizations using each of these techniques; the resulting data highlighted the strength of DOSY for convenient monitoring of polymer synthesis.

\section{Results and discussions}

For a spherical particle of radius $\mathrm{R}_{\mathrm{H}}$, the Stokes-Einstein equation ${ }^{11}$ describes the diffusion coefficient in eq 1 ,

$$
D=\frac{k T}{6 \pi \eta R_{H}}
$$

where $\mathrm{k}$ is the Boltzmann constant, $\mathrm{T}$ is the absolute temperature, and $\eta$ is the solvent viscosity. Based on eq 1, Johnson noted that for a monodispersed polymer system, D can be correlated to molar mass $\mathrm{M}$ described in eq 2, ${ }^{14}$

$$
D=A M^{\alpha}
$$

where $\mathrm{A}$ and $\mathrm{a}$ are constants that correlates to different polymers. Equation 2 can be linearized by taking the logarithm of both sides to yield equation 3 ,

$$
\log D=\alpha \log M+\log A
$$

For a class of macromolecules with an approximate constancy in density and similarity in shape, the relation of $\mathrm{D}$ and $\mathrm{M}$ is shown in eq $4,{ }^{48}$

$$
M \approx(C / D)^{d_{f}}
$$

where $\mathrm{d}_{\mathrm{f}}$ is the fractal dimension of molecules and $\mathrm{C}$ is a constant. Taking the logarithm of both sides results in eq 5 ,

$$
\log D=d_{f} \log M+\log C
$$

Equation 5 is empirically identical to equation 3 on condition that the shape of a set of analyte compounds remains similar. ${ }^{48}$ Moreover, introducing equation $6: \mathrm{R}_{\mathrm{H}}=(3 \mathrm{M} /$ $\left.4 \pi \rho N_{A}\right)^{1 / 3}$ ( $\rho$ is the density of the liquid, $N_{A}$ is the Avogadro constant) to the StokesEinstein equation 1 resulted in equation $7,{ }^{22}$

$$
\log D=-\frac{1}{3} \log M+\frac{1}{3} \log \rho-\log \eta-\frac{1}{3} \log \frac{162 \pi^{2}}{k^{3} T^{3} N_{A}} \quad \text { (7) }
$$

To obtain a linear relationship between $\log \mathrm{D}$ and $\log \mathrm{M}$, convection, density change, and viscosity variation must be well controlled. Since the Stokes-Einstein equation is valid for 
particles at least five times larger than the solvent molecules and under infinitely diluted condition, it is highly applicable to diluted polymer solutions. Diluted solvent will assure consistant viscosity and density conditions, so that a linear correlation between $\log \mathrm{D}$ and $\log \mathrm{M}$ can be achieved.

We therefore postulated that for all our measurements towards external calibration curves and kinetic analysis of polymerization, highly diluted reaction mixture samples can be measured separately to give reliable and comparable diffusion coefficients by DOSY. By creating the linear calibration curve between $\log \mathrm{D}$ and $\log \mathrm{Mw}$ of known narrowly dispersed polymers, the molecular weight of unknown polymers can be caculated with the measured diffusion coeffcient. In order to prove this hypothesis, calibration curves between $\log \mathrm{D}$ and $\log \mathrm{Mw}$ of a set of five selected narrowly dispersed polymers were determined by $\mathrm{D}-\mathrm{Mw}$ analysis as a first step.

Polystyrene (PS) commercial standards were selected to construct the calibration curve due to its general use as GPC standards. Narrowly dispersed polymers were used to generate the D-Mw plot calibration to reduce the discrepancy of number average molecular weight and weight average molecular weight. Benzene was selected as the solvent due to its relatively high viscosity $\left(0.603 \mathrm{cp} \text { at } 25^{\circ} \mathrm{C}\right)^{49}$ and its ability to solvate a wide variety of organic polymers.

Considering the large molecular weights of polystyrene standards, full signal attenuation during DOSY experiments were achieved $(<5 \%)$ by prolonged diffusion time to ensure valid values of diffusion coefficients. Table 1 and Figure 1 showed the detailed results of the PS calibration curve in benzene. The high $\mathrm{r}^{2}$ value of 0.9991 demonstrated excellent linearality of the $\log$ D- $\log \mathrm{Mw}$ curve. Remarkably, if extrapolating the calibration curve from $9000 \mathrm{~g} /$ mol to low molecular range, the $\mathrm{Mw}$ of benzene was predicted as $73 \mathrm{~g} / \mathrm{mol}$, with only $6.4 \%$ deviation of its calculated value. The successful establishment of the polystyrene-based calibration curve in organic system facilitated further kinetic analysis for living polymerization.

We then performed a model ATRP experiment to examine our method. ATRP is the most widely used living radical polymerization because of its high control in polymerization and versatile applications in material science. In ATRP, good control of radical polymerization can be obtained through reversible and repeatable activation/deactivation of dormant species containing propagating radicals in the presence of transition metal complex. ${ }^{36}$ In our experiment, ATRP of styrene $\mathbf{1}$ took placed with commonly used copper/nitrogen ligand complex, $\mathrm{CuBr}$ and $\mathrm{N}, \mathrm{N}, \mathrm{N}^{\prime}, \mathrm{N}^{\prime \prime}, \mathrm{N}^{\prime \prime}$-pentamethyldiethylenetriamine (PMDETA), and alkyl halide, methyl 2-bromoisobutyrate in anisole. Kinetic aliquots were taken from the polymerization solution at each designated time interval. Mw of each aliquot was characterized by both GPC and DOSY. Diffusion coefficients were obtained after full attenuation of NMR signals. Diffusion coefficients of the samples were fitted to the PS calibration curve (Figure 1) to calculate the Mw. The aliquot was analysed by GPC with multi-angle laser light scattering in THF eluent to determine absolute molecular weights of polymers.

The molecular weights of polystyrene $\mathbf{3}$ linearly increased with conversions showing a typical ATRP behavior (Table 2, Figure 2). Between the range of 5,500 to 26,900 g/mol (data from GPC), the deviation ranged from $0.4 \%$ to $6.4 \%$. Most importantly, the results from both GPC and DOSY were closely correlated. The number average Mn of the final polymer sample at $2700 \mathrm{~min}$ was determined to be $265000 \mathrm{~g} / \mathrm{mol}$ by end-group analysis, based on the purified polystyrene sample redissolved in benzene. Thus, the Mw and $\mathrm{Mn}$ given from NMR data can yield a PDI value of 1.02, consistent with GPC measurement. 
We stacked six DOSY spectra of ATRP aliquots at different time points ranging from $2 \mathrm{~h}$ to the end point of $45 \mathrm{~h}$ (Figure 3). The diffusion coefficient of styrene monomer 1 remained unchanged at $17.65 \times 10^{-10} \mathrm{~m}^{2} / \mathrm{s}$, which demonstrated a good viscosity control by solvent dilution. The polystyrene 3 chain continued elongating with increasing values of hydrodynamic radii and reached a Mw of $26900 \mathrm{~g} / \mathrm{mol}$ after $45 \mathrm{~h}$. Since the chemical shifts of monomer and polymer overlapped at aromatic regions, only olefinic and alkyl regions were displayed. The stacked DOSY spectrum was a vivid and informative portrait of this living polymerization process.

This model kinetic study of styrene ATRP demonstrated a close correlation between conventional GPC molecular weight determination method and the DOSY molecular weight determination method over a wide range of molecular weights. Compared to conventional GPC molecular weight measurement, the measuring time for DOSY was 4 minutes, about one tenth of the time commonly required for GPC. Moreover, since we used highly diluted samples for ${ }^{1} \mathrm{H}$ DOSY measurement, the amount of reaction sample required was less than $10 \%$ of that for GPC. As such, this DOSY technique is advantageous to perform large quantity measurement for kinetic analysis as well as smaller reaction setup for catalyst evaluation.

Based on the exciting results from ATRP, we continued to assess reversible additionfragmentation chain-transfer polymerization (RAFT) kinetic aliquot as another example of living polymerization. The PS calibration curve with the region between 5,000 and 30,000 g/ mol was enhanced by incorporating four data points obtained from ATRP measurements for more accurate $\mathrm{Mw}$ prediction of RAFT polymers. The enhanced calibration curve ( $\mathrm{y}=$ $-0.537 \times-7.695$ ) showed an increased $\mathrm{r}^{2}$ value of 0.9997 with improved accuracy in the lower Mw range (Figure S26, Table S4).

We next analyzed a typical RAFT polymerization of styrene $\mathbf{1}$ in a similar fashion. In our experiment, trithiocarbonate CTA, 2-(dodecylthiocarbonothioylthio)-2-methylpropionic acid 4 were used to perform RAFT which was initiated by thermal initiator

azobisisobutyronitrile. We randomly sampled the reaction crude at four time points to verify agreement in molecular weights for both GPC and DOSY experiments (Table 3). The molecular weights obtained from GPC and DOSY were within less than 7\% deviation between $5,000 \mathrm{~g} / \mathrm{mol}$ and $90,000 \mathrm{~g} / \mathrm{mol}$. In general, higher molecular weight polymer indicated higher agreement between DOSY and GPC values than the lower molecular weight instance. The values of diffusion coefficient of styrene were all close to $17.65 \times 10^{-10}$ $\mathrm{m}^{2} / \mathrm{s}$, suggesting good viscosity control between each sample. The chain growth of polystyrene $\mathbf{5}$ over time was conveniently monitored by the decreasing values of diffusion coefficient (Figure 4).

Living polymerization ATRP and RAFT of styrene were proved to be highly agreeable in molecular weight determination by both GPC and DOSY measurement over a wide range of molecular weights. Finally, ROMP was examined to broaden the utility of our method for controlled polymerization.

To begin, two representative polycyclooctenes with $\mathrm{Mw}$ of $9,800 \mathrm{~g} / \mathrm{mol}$ and 71,800 g/mol (GPC data) were prepared separately with the $2^{\text {nd }}$ generation catalyst $\mathbf{8}$ in dichloromethane. The molecular weights of the polycyclooctene samples were predicted to be $9,700 \mathrm{~g} / \mathrm{mol}$ and $68,900 \mathrm{~g} / \mathrm{mol}$ by the PS calibration curve (Figure 1), with $1.2 \%$ and $3.9 \%$ deviation from the GPC values, respectively. The PS-based calibration plot was tailored again for ROMP type linear polymers by incorporating the two polycyclooctene samples into the existing curve (Figure S27). The $\mathrm{r}^{2}$ of overall calibration plot increased from 0.9991 to 0.9998 , and 
the molecular weight prediction differences of the polycyclooctene samples were reduced to $0.4 \%$ and $3.1 \%$ (Table S6).

Stacking five DOSY spectra of polystyrene and polycycloocetene (poly(COE)) standards resulted in a spectrum resembling that from a typical gel electrophoresis (Figure 5). The benzene and polystyrene standards resonances at $\delta 7.15 \mathrm{ppm}$ and $7.00 \mathrm{ppm}$ lined up at various diffusion coefficients according to their molecular weights. The polycyclooctene resonances at $\delta 5.50 \mathrm{ppm}, 2.12 \mathrm{ppm}$, and $1.35 \mathrm{ppm}$ diffused at the same level, with one set of resonances close to polystyrene with a $\mathrm{Mw}$ of $9,000 \mathrm{~g} / \mathrm{mol}$, and the other set higher than polystyrene with a $\mathrm{Mw}$ of $600,000 \mathrm{~g} / \mathrm{mol}$. This intriguing observation implies the possibility of using this method on the determination of molecular weights of biological relevant macromolecules.

The polymerization process of ROMP of 1,5-cyclooctadiene (COD) 6 was initiated by the $2^{\text {nd }}$ generation catalyst $\mathbf{8}$ after 5 minutes (Figure 6). The conversion rate was proportional to the increase in molecular weight. Over a period of 45 minutes, the molecular weight of polyCOD 7 reached 29,600 g/mol with 100\% conversion (Figure 6 and Figure 7). The Mw conversion plot yielded a non-linear curve with a slope change after $20 \%$ conversion. The diffusion coefficients of the newly generated polyCOD 7 resonance at $\delta 5.50 \mathrm{ppm}$ decreased from 10 minutes to 45 minutes from the stacked DOSY spectrum (Figure 8).

The DOSY polymer molecular weight determination method was utilized to evaluate polymerizations process of various olefin metathesis catalysts as an additional application. We used the $2^{\text {nd }}$ generation $\mathbf{8}$ and $3^{\text {rd }}$ generation $\mathbf{9}$ catalysts to polymerize cyclooctene $\mathbf{1 0}$ by ROMP in DCM and THF (Figure 9). The $3^{\text {rd }}$ generation catalyst 9 is known to be a fast initiating catalyst for ROMP. The resulting data indicated that $\mathbf{9}$ initiated the polymerization of COE 10 immediately upon addition to the reaction mixture and completed the reaction in $20 \mathrm{~min}$, generating 11 with a predicted $\mathrm{Mw}$ of $52,700 \mathrm{~g} / \mathrm{mol}$. In contrast, the polymerization catalyzed by $\mathbf{8}$ did not commence until $20 \mathrm{~min}$. However, the final molecular weight of $\mathbf{1 1}$ polymerized by 9 was $56,700 \mathrm{~g} / \mathrm{mol}$, lower than that catalyzed by $8(84,900 \mathrm{~g} / \mathrm{mol})$. Additionally, ${ }^{1} \mathrm{H}$ DOSY and ${ }^{1} \mathrm{H}$ NMR experiments showed that ROMP by 8 in THF was slow with low conversion, due to the coordinating nature of THF towards active catalytic species in solution. ${ }^{50}$ These successful examples of ROMP revealed a facile access to new olefin polymerization catalysts evaluation and reaction condition optimization by this method.

\section{Conclusions}

A new diffusion NMR-based method to determine the molecular weight of linear and narrowly dispersed polymers is reported. Narrowly dispersed polystyrene-based calibration curves have been established using linear relation of $\log \mathrm{D}$ and $\log \mathrm{Mw}$ to determine weightaverage molecular weight of linear flexible polymers. The calibration curve can be utilized to accurately monitor the polymerization proceeding of three commonly used polymerizations: ATRP, RAFT and ROMP. The Mw of polymers determined by DOSY showed excellent agreement with the corresponding GPC data. The calibration curve of PS was tailored twice with ATRP PS and ROMP polyCOE to adapt to various types of linear polymers for more accurate prediction. Moreover, this method was successfully applied to ROMP to monitor kinetics of polymerization catalyst efficiency. It may replace many conventional polymer molecular weight determination methods including GPC, owing to its short measurement time, low sample loading, and high accuracy at low molecular range. One example of measurement of polydispersity index (defined as Mw/Mn) was given in ATRP experiments using DOSY (Mw) and end-group analysis (Mn) data. More accurate 
results of PDI can be determined by designing and applying specially modified catalysts or initiators to enhance NMR signals and reduce integration errors.

\section{EXPERIMENTAL SECTION}

\section{Materials and General Methods}

Benzene- $d_{6}$ was kept with $4 \AA$ molecular sieves under argon. 1, 5- cyclooctadiene, cyclooctene, $\mathrm{Cu}(\mathrm{I}) \mathrm{Br}(99.999 \%), \mathrm{N}, \mathrm{N}, \mathrm{N}^{\prime}, \mathrm{N}^{\prime \prime}, \mathrm{N}^{\prime \prime}$-pentamethyldiethylenetriamine (PMDETA), methyl 2-bromoisobutyrate, 2-(Dodecylthiocarbonothioylthio)-2methylpropionic acid (DDMAT) azobisisobutyronitrile (AIBN) and styrene were obtained from Aldrich Chemical Co., and used as received. Polystyrene commercial standards were purchased from Polysciences Inc. ( $9000 \mathrm{~g} / \mathrm{mol}, 60000 \mathrm{~g} / \mathrm{mol}$, and $80000 \mathrm{~g} / \mathrm{mol}$ ), Pressure Chemical Co. (30000 g/mol and 200000 g/mol), and Shodex Denko America (156000 g/ mol).

\section{ATRP experiments}

In a Schlenk flask, $\mathrm{CuBr}$ (50 mg), PMDETA (60.4 mg) and methyl 2-bromoisobutyrate (63 $\mathrm{mg}$ ) were placed. The solid reagents containing Schlenk flask was repeatedly vacuumed and backfilled with dry argon for three times. Degased styrene $(7.3 \mathrm{~g})$ and Anisole $(8 \mathrm{ml})$ were added to the solid reagent containing Schlenk flask. The first aliquot was taken prior to placing the reaction mixture in $90{ }^{\circ} \mathrm{C}$ oil bath. Kinetic aliquots $(0.3 \mathrm{ml})$ were taken at designated times for DOSY and GPC characterization. For each aliquot, the polymerization was stopped by removing heat followed by exposure the reaction solution in the air. The polymer solution was filtered through neutral alumina packed column to remove copper complex.

\section{RAFT experiments}

All solid reagents, DDMAT (100 mg), AIBN (9 mg) were placed in Schlenk flask and the Schlenk flask was repeatedly vacuumed and backfilled with dry argon for three times. Degased styrene $(5.7 \mathrm{~g})$ and anisole $(6.3 \mathrm{ml})$ were added to the Schlenk flask and then the reaction mixture was degased by argon bubbling. The reaction mixture was heated at $70{ }^{\circ} \mathrm{C}$ with stirring. Aliquots $(0.3 \mathrm{ml})$ were taken at designated times for DOSY and GPC characterization.

\section{ROMP experiments}

In a flame-dried and argon-charged $50 \mathrm{~mL}$ flask was added $1.696 \mathrm{mg}(0.002 \mathrm{mmol})$ The $2^{\text {nd }}$ generation "Sheng Ding" catalyst 8 and $20 \mathrm{~mL}$ dry dichloromethane at room temperature. Timing was started as soon as $1.230 \mathrm{~mL}(10 \mathrm{mmol}) 1,5$ - cyclooctadiene was injected into the solution. $1 \mathrm{~mL}$ aliquots were extracted via syringe from the reaction mixture at designated times into a scintillation vial with two drops of ethyl vinyl ether. $40 \mu \mathrm{L}$ of the quenched reaction mixture were transferred to an NMR tube and diluted with $1 \mathrm{~mL}$ of benzene- $d_{6}$ for NMR experiments.

\section{NMR experiments}

All NMR tubes were flame dried and evacuated in vacuo in advance. NMR experiments were performed at $25 \pm 1{ }^{\circ} \mathrm{C}$. All NMR samples were stabilized at $25^{\circ} \mathrm{C}$ for $5 \mathrm{~min}$ before data collection. For polystyrene standard samples, each NMR tube contained $0.5 \mathrm{mg}$ polystyrene and $1 \mathrm{~mL}$ benzene- $d_{6}$. For ATRP, RAFT, and ROMP samples, each NMR tube contained $40 \mu \mathrm{L}$ reaction mixture and $1 \mathrm{~mL}$ benzene- $d_{6}$. DOSY experiments were performed on a Bruker DRX 300 spectrometer equipped with an Accustar $Z$-axis gradient amplifier and an ATMA BBO probe with a z-axis gradient coil. All experiments were run without 
spinning to avoid convection. Maximum gradient strength was $0.214 \mathrm{~T} / \mathrm{m}$. The standard Bruker pulse program, stegp1s, employing a stimulated echo sequence and 1 spoil gradient was utilized. Bipolar rectangular gradients were used with a total duration of $0.5-10 \mathrm{~ms}$ (7 $\mathrm{ms}$ for polystyrene measurement). Gradient recovery delays were $0.5-1 \mu \mathrm{s}$. Diffusion times were between 100-2000 ms ( $200 \mathrm{~ms}$ for polystyrene measurement). The number of gradient steps was set to be 32. Individual rows of the quasi-2-D diffusion databases were phased and baseline corrected. DOSY spectra were processed by Topspin 1.3 software. Diffusion dimension was generated using inverse Laplace Transform driven by maximum entropy method. ${ }^{22}$ Diffusion coefficients of a chosen narrow chemical shift range were extracted from T1/T2 analysis module of Topspin 1.3 calculated by the maximum entropy (GIFA) method developed by Delsuc et al. ${ }^{51}$ Unless otherwise mentioned, the DOSY spectrum was processed without additional change of processing parameters.

\section{GPC characterization}

GPC analysis of polymer was performed by two PLgel $10 \mu \mathrm{m}$ mixed-B LS columns (Polymer Laboratories) connected in series with a DAWN EOS multiangle laser light scattering (MALLS) detector (Wyatt Technology), an Optilab DSP differential refractometer (Wyatt Technology), and a ViscoStar viscometer (Wyatt Technology) in THF eluent. The analysis was performed with a flow rate of $1 \mathrm{ml} / \mathrm{min}$ at room temperature. Absolute molecular weights and PDI were calculated from $\mathrm{dn} / \mathrm{dc}$ values that were obtained by assuming $100 \%$ mass elution from the GPC columns.

\section{Supplementary Material}

Refer to Web version on PubMed Central for supplementary material.

\section{Acknowledgments}

Financial support by NIH (R01 GM031332-28) is acknowledged. The authors thank Marc M. Baum at the Oak Crest Institute for generously providing Bruker $300 \mathrm{MHz}$ NMR for diffusion experiments. We also thank Prof. Paul G. Williard at Brown University for constructive advices.

\section{REFERENCES}

1. Mark, J.; Ngai, K.; Graessley, W.; Mandelkern, L.; Samulski, E.; Koenig, J.; Wignall, G. Physical properties of polymers. 3rd ed.. Cambridge: Cambridge University Press; 2004.

2. Flory, PJ. Principles of Polymer Chemistry. Ithaca: Cornell University Press; 1953.

3. Allcock, HR.; Lampe, FW.; Mark, JE. Contemporary Polymer Chemistry. 3rd ed.. Upper Saddle River, N.J: Pearson/Prentice Hall; 2003. p. 393-491.

4. Stevens, MP. Polymer chemistry: an introduction. 3rd ed.. Oxford univeristy press; 1999. p. 35-60.

5. Young, RJ.; Lovell, PA. Introduction to polymers. 3rd ed.. CRC Press; 2011. p. 269-341.

6. Carraher, CEJ. Carraher's polymer chemistry. 8th ed.. CRC Press; 2011. p. 55-91.

7. Fried, JR. Polymer science and technology. 1st ed.. Englewood Cliffs: Prentice Hall PTR; 1995. p. 110-131.

8. Cowie, JMG.; Arrighi, V. Polymers : chemistry and physics of modern materials. 3rd ed.. Boca Raton: CRC Press; 2008. p. 229-252.

9. Young, RJ.; Lovell, PA. Introduction to polymers. 3rd ed.. CRC Press; 2011. p. 343-380.

10. Elias, H-G. Macromolecules. Vol. Vol. 1. Darmstadt: WILEY-VCH; 2005. p. 109-151.

11. Cohen Y, Avram L, Frish L. Angew. Chem., Int. Ed. 2005; 44:520-554.

12. Johnson CS Jr. Prog. Nucl. Magn. Reson. Spectrosc. 1999; 34:203-256.

13. Morris KF, Johnson CS. J. Am. Chem. Soc. 1992; 114:3139-3141.

14. Chen A, Wu D, Johnson CS. J. Am. Chem. Soc. 1995; 117:7965-7970. 
15. Morris KF, Johnson CS. J. Am. Chem. Soc. 1993; 115:4291-4299.

16. Valentini M, Vaccaro A, Rehor A, Napoli A, Hubbell JA, Tirelli N. J. Am. Chem. Soc. 2004; 126:2142-2147. [PubMed: 14971949]

17. Cain JB, Zhang K, Betts DE, DeSimone JM, Johnson CS. J. Am. Chem. Soc. 1998; 120:93909391.

18. Masuda A, Ushida K, Koshino H, Yamashita K, Kluge T. J. Am. Chem. Soc. 2001; 123:1146811471. [PubMed: 11707125]

19. Pregosin PS, Kumar PGA, Fernández I. Chem. Rev. 2005; 105:2977-2998. [PubMed: 16092825]

20. Pregosin PS, Martinez-Viviente E, Kumar PGA. Dalton Trans. 2003:4007-4014.

21. Dehner A, Kessler H. Chembiochem. 2005; 6:1550-1565. [PubMed: 16138303]

22. Li D, Keresztes I, Hopson R, Williard PG. Acc. Chem. Res. 2009; 42:270-280. [PubMed: 19105594]

23. Viéville J, Tanty M, Delsuc M-A. J. Magn. Reson. 2011; 212:169-173. [PubMed: 21788147]

24. Braunecker WA, Tsarevsky NV, Gennaro A, Matyjaszewski K. Macromolecules. 2009; 42:63486360.

25. Clark PG, Guidry EN, Chan WY, Steinmetz WE, Grubbs RH. J. Am. Chem. Soc. 2010; 132:34053412. [PubMed: 20158251]

26. Momcilovic N, Clark PG, Boydston AJ, Grubbs RH. J. Am. Chem. Soc. 2011; 133:19087-19089. [PubMed: 22023086]

27. Ma L, Hopson R, Li D, Zhang Y, Williard PG. Organometallics. 2007; 26:5834-5839.

28. Li D, Hopson R, Li W, Liu J, Williard PG. Org. Lett. 2008; 10:909-911. [PubMed: 18251549]

29. Li D, Sun C, Liu J, Hopson R, Li W, Williard PG. J. Org. Chem. 2008; 73:2373-2381. [PubMed: 18294002]

30. Liu J, Li D, Sun C, Williard PG. J. Org. Chem. 2008; 73:4045-4052. [PubMed: 18459811]

31. Kagan G, Li W, Hopson R, Williard PG. Org. Lett. 2009; 11:4818-4821. [PubMed: 19788266]

32. Li W, Kagan G, Yang H, Cai C, Hopson R, Dai W, Sweigart DA, Williard PG. Organometallics. 2010; 29:1309-1311.

33. Li W, Kagan G, Yang H, Cai C, Hopson R, Sweigart DA, Williard PG. Org. Lett. 2010; 12:26982701. [PubMed: 20481557]

34. Kagan G, Li W, Li D, Hopson R, Williard PG. J. Am. Chem. Soc. 2011; 133:6596-6602. [PubMed: 21486016]

35. Kagan G, Li W, Sun C, Hopson R, Williard PG. J. Org. Chem. 2011; 76:65-70. [PubMed: 21141914]

36. Matyjaszewski K. Macromolecules. 2012; 45:4015-4039.

37. Braunecker WA, Matyjaszewski K. Prog. Polym. Sci. 2007; 32:93-146.

38. Matyjaszewski K, Xia JH. Chem. Rev. 2001; 101:2921-2990. [PubMed: 11749397]

39. Moad G, Rizzardo E, Thang SH. Aust. J. Chem. 2009; 62:1402-1472.

40. Moad G, Rizzardo E, Thang SH. Aust. J. Chem. 2006; 59:669-692.

41. Moad G, Rizzardo E, Thang SH. Aust. J. Chem. 2005; 58:379-410.

42. Moad G, Rizzardo E, Thang SH. Polymer. 2008; 49:1079-1131.

43. Bielawski CW, Grubbs RH. Prog. Polym. Sci. 2007; 32:1-29.

44. Vougioukalakis GC, Grubbs RH. Chem Rev. 2010; 110:1746-1787. [PubMed: 20000700]

45. Sutthasupa S, Shiotsuki M, Sanda F. Polym. J. 2010; 42:905-915.

46. Leitgeb A, Wappel J, Slugovc C. Polymer. 2010; 51:2927-2946.

47. Boyer C, Bulmus V, Davis TP, Ladmiral V, Liu JQ, Perrier S. Chem. Rev. 2009; 109:5402-5436. [PubMed: 19764725]

48. Floquet, Sb; Brun, Sb; Lemonnier, J-Fo; Henry, M.; Delsuc, M-A.; Prigent, Y.; Cadot, E.; Taulelle, F. J. Am. Chem. Soc. 2009; 131:17254-17259. [PubMed: 19904936]

49. Reynolds WW, Gebhart HJ. J. Chem. Eng. Data. 1960; 5:220-225.

50. Stark A, Ajam M, Green M, Raubenheimer HG, Ranwell A, Ondruschka B. Adv. Synth. Catal. 2006; 348:1934-1941. 
51. Delsuc MA, Malliavin TE. Anal Chem. 1998; 70:2146-2148. 


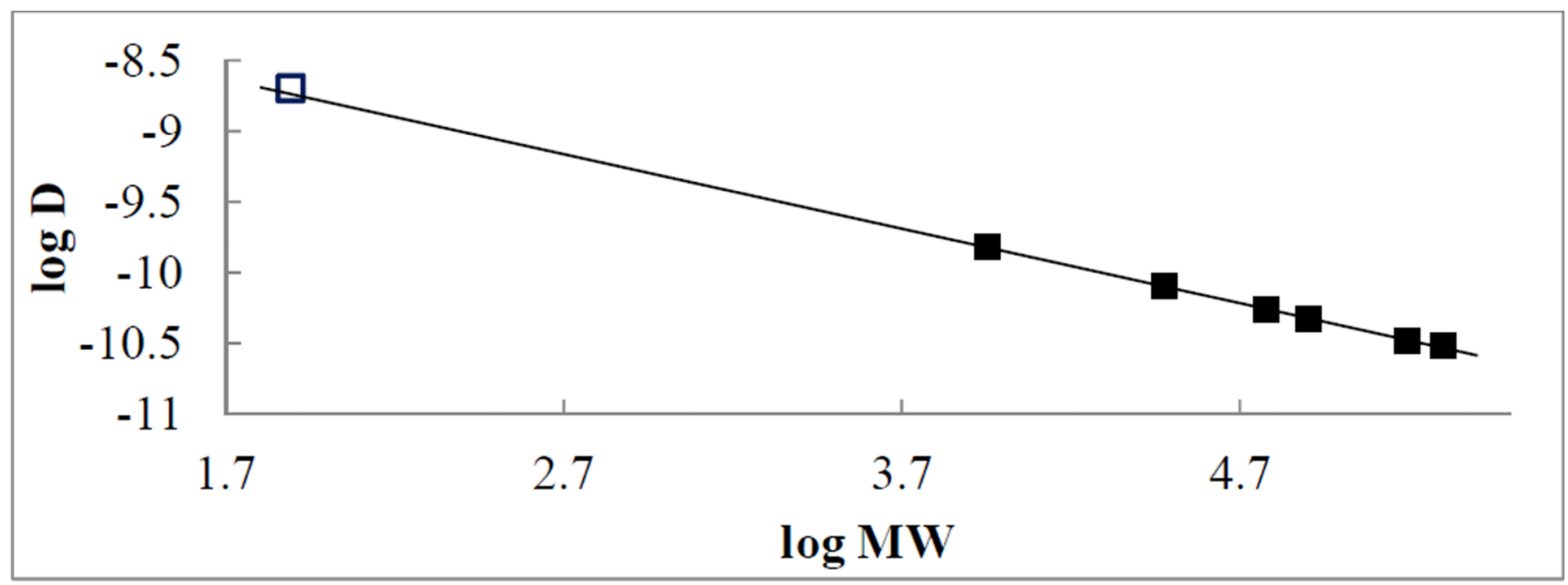

Figure 1.

PS calibration curve in benzene- $d_{6}$ for Mw prediction. Black solid square: PS standards, blue open square: benzene. 


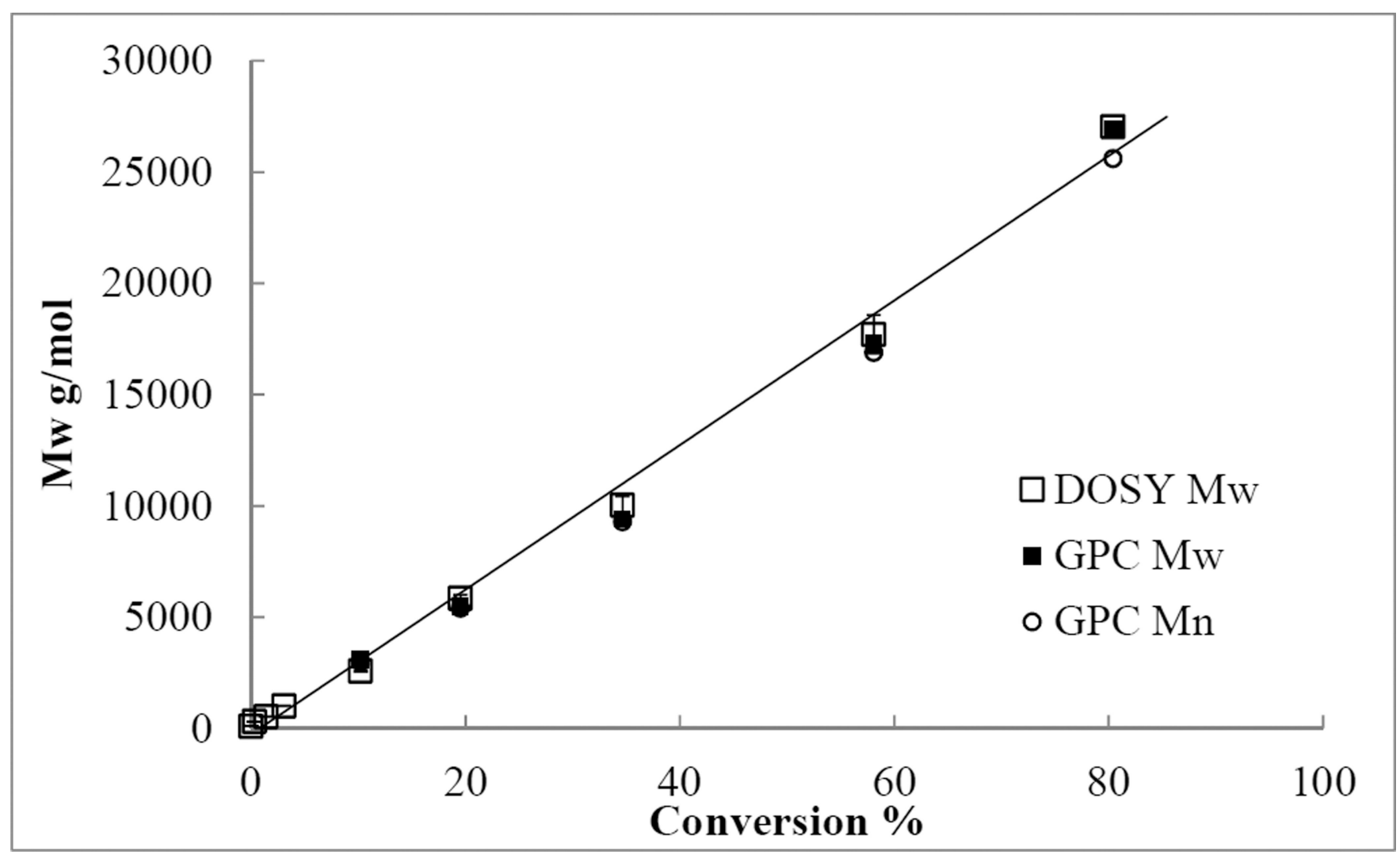

Figure 2.

Conversion-Mw plot of polymerization of styrene by ATRP. Black solid square: DOSY Mw, black open square: GPC Mw, black open circle: GPC Mn. 


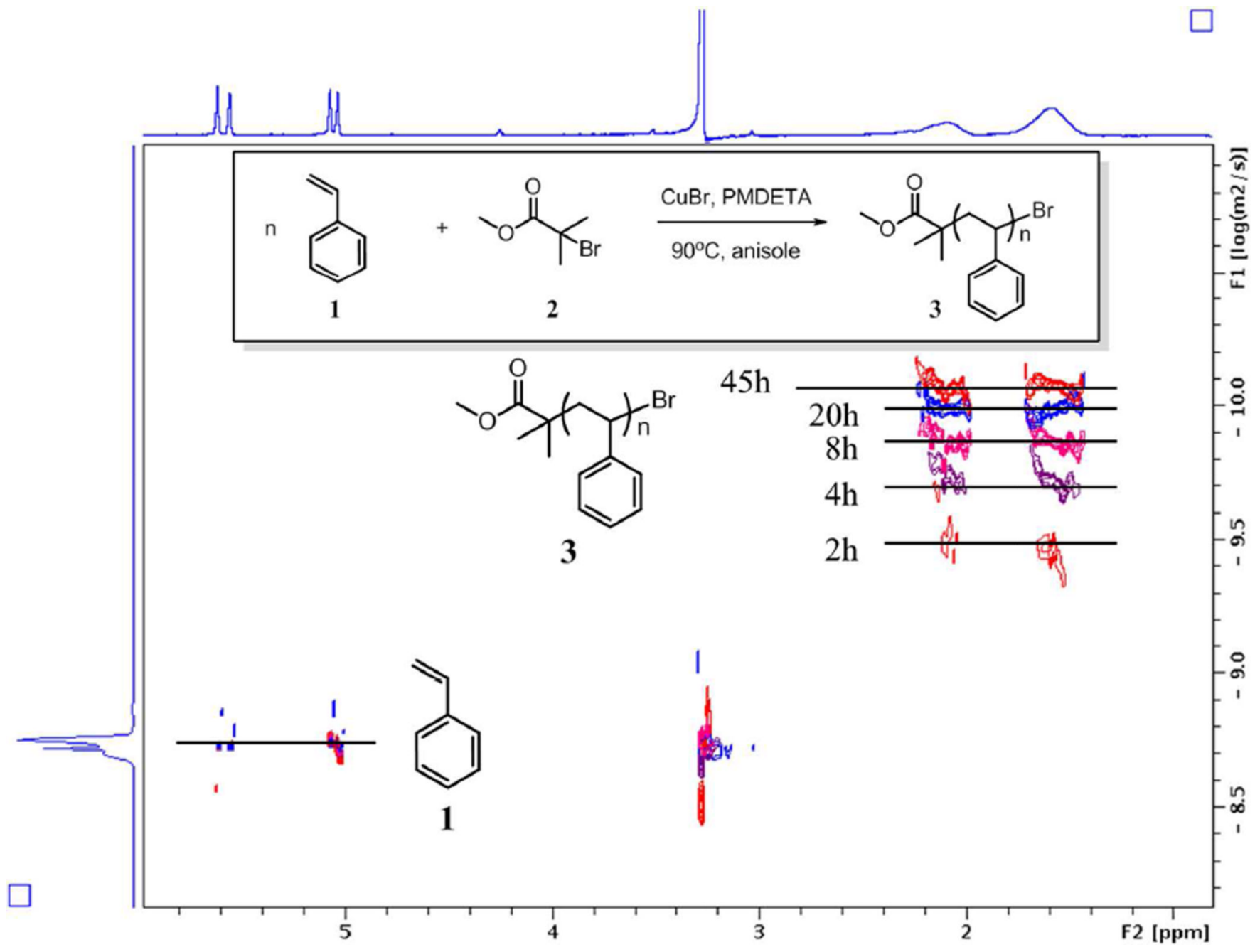

Figure 3.

Stacked DOSY spectra of reaction crude of ATRP. DOSY spectra of $0 \mathrm{~h}, 2 \mathrm{~h}, 4 \mathrm{~h}, 8 \mathrm{~h}, 20 \mathrm{~h}$, and $45 \mathrm{~h}$ were stacked. $\mathrm{X}$-axis demonstrates all the ${ }^{1} \mathrm{H}$ resonances of the components in solution. $\mathrm{Y}$-axis is the diffusion dimension. Olefinic peaks of styrene were used as internal references to monitor the viscosity change of the dilute crude solution. Due to the heavy overlap of the aromatic regions of styrene and polystyrene, they are not shown in the stacked spectra. Representative ATRP ${ }^{1} \mathrm{H}$ DOSY spectrum can be found in Figure S20. 


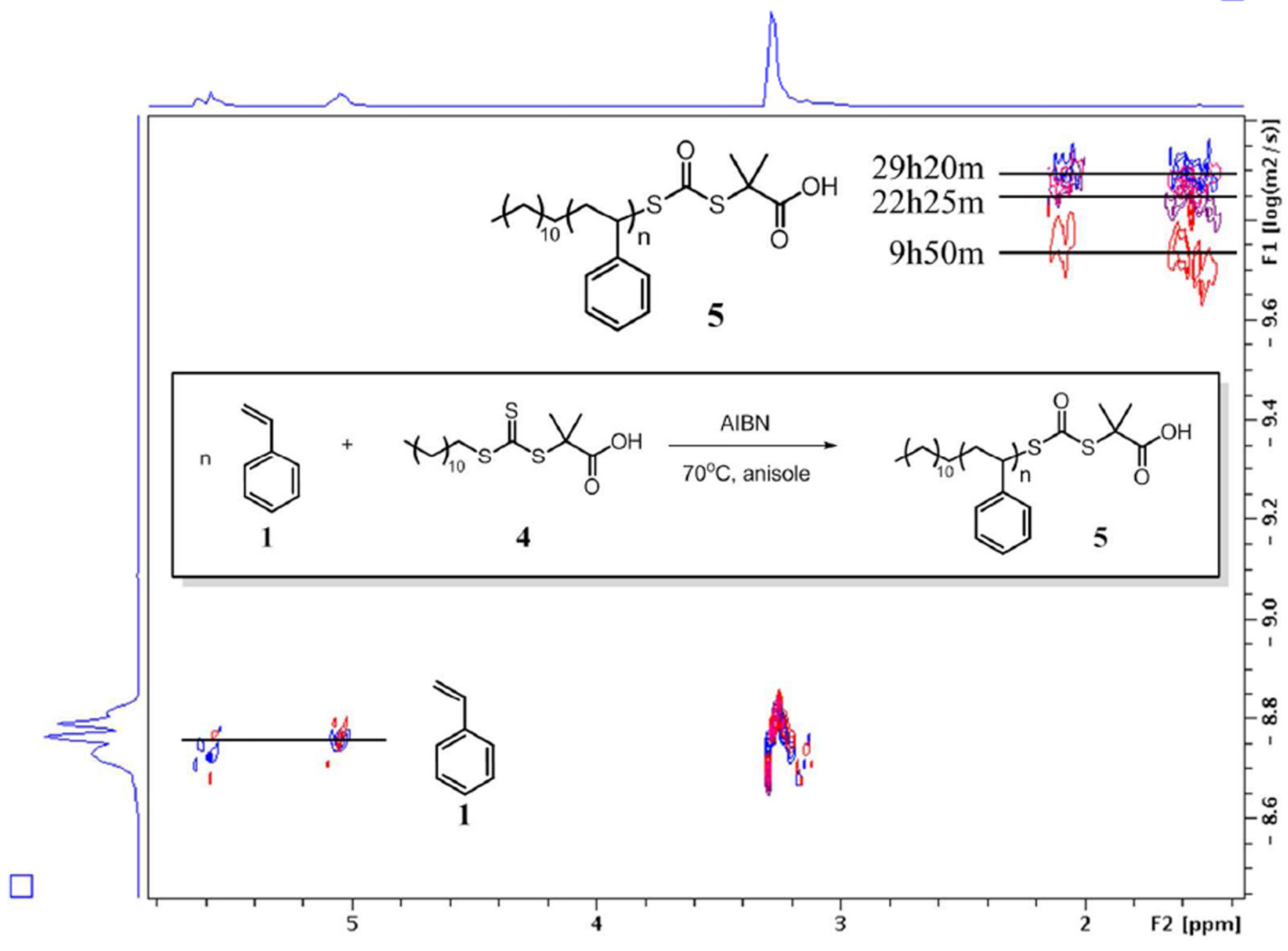

Figure 4.

Stacked DOSY spectra of reaction crude of RAFT. DOSY spectra of 0h, 9h50m, 22h25m, and $29 \mathrm{~h} 20 \mathrm{~min}$ were stacked. Olefinic peaks of styrene were used as internal references to monitor the viscosity change of the dilute crude solution. Due to the heavy overlap of the aromatic regions of styrene and polystyrene, they are not shown in the stacked spectra. Representative RAFT ${ }^{1} \mathrm{H}$ DOSY spectra can be found in supplementary Figure S21. 


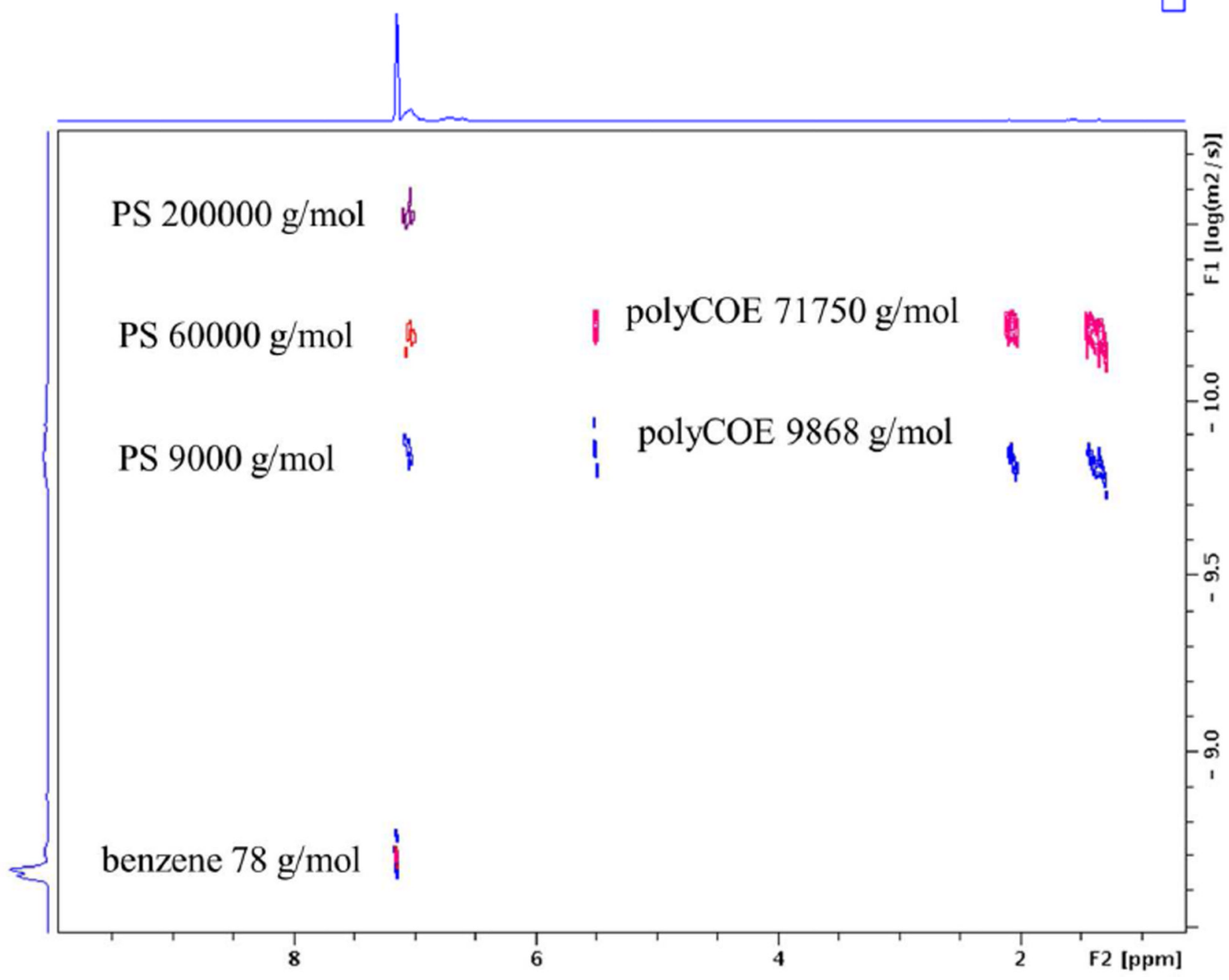

Figure 5.

Stacked DOSY spectra of polystyrene standards and polycycloocetene standards. We chose polystyrene with molecular weight of $9000 \mathrm{~g} / \mathrm{mol}, 60000 \mathrm{~g} / \mathrm{mol}$, and $200000 \mathrm{~g} / \mathrm{mol}$ and polycyclooctene with molecular weight of $9800 \mathrm{~g} / \mathrm{mol}$ and $71800 \mathrm{~g} / \mathrm{mol}$ as representative examples. 


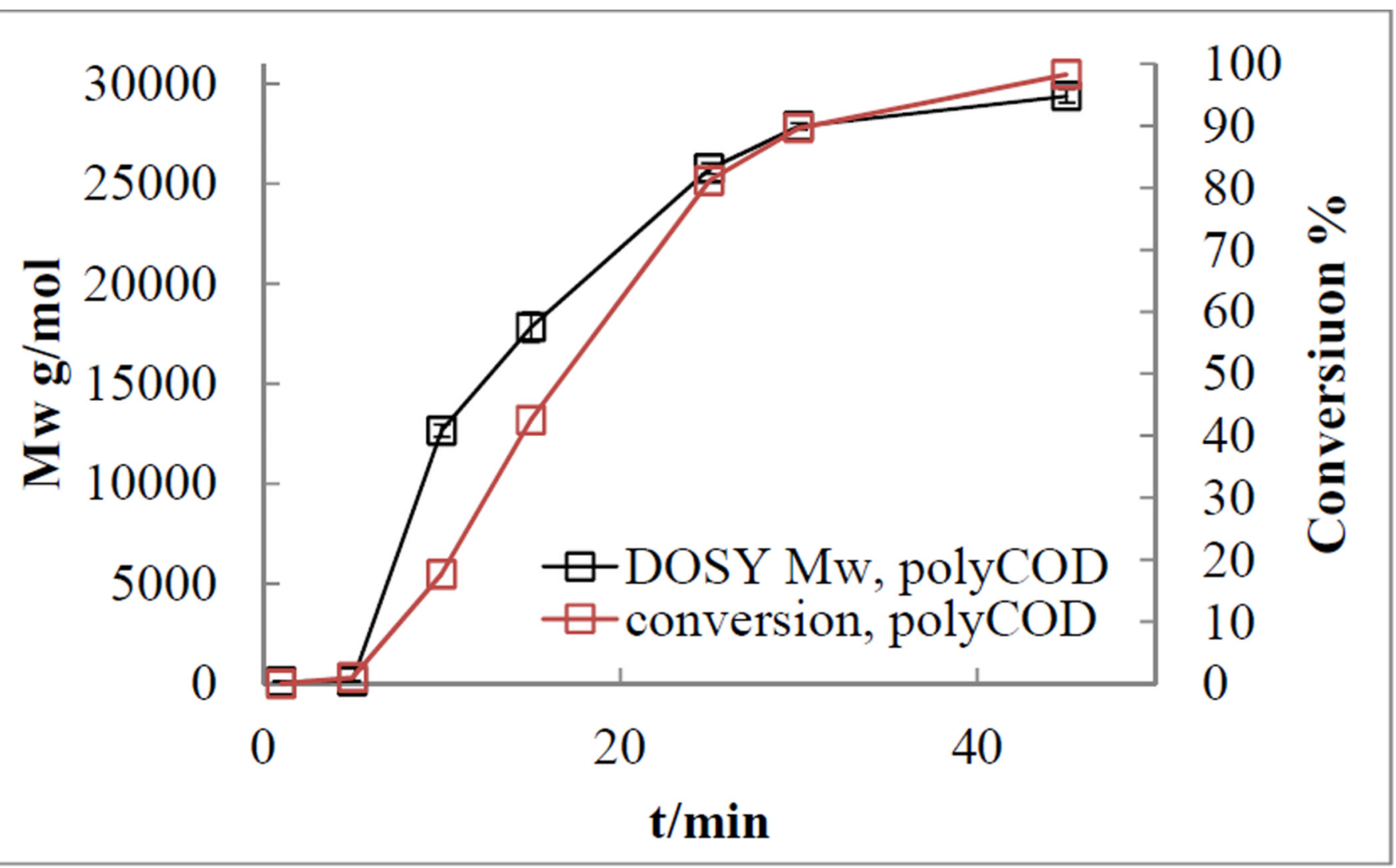

Figure 6.

Mw-t plot and conversion-t plot of polymerization of 1,5-cyclooctadiene by ROMP. Black open square: weight-average molecular weight provided by ${ }^{1} \mathrm{H}$ DOSY. Red open square: conversion calculated from ${ }^{1} \mathrm{H}$ NMR. 


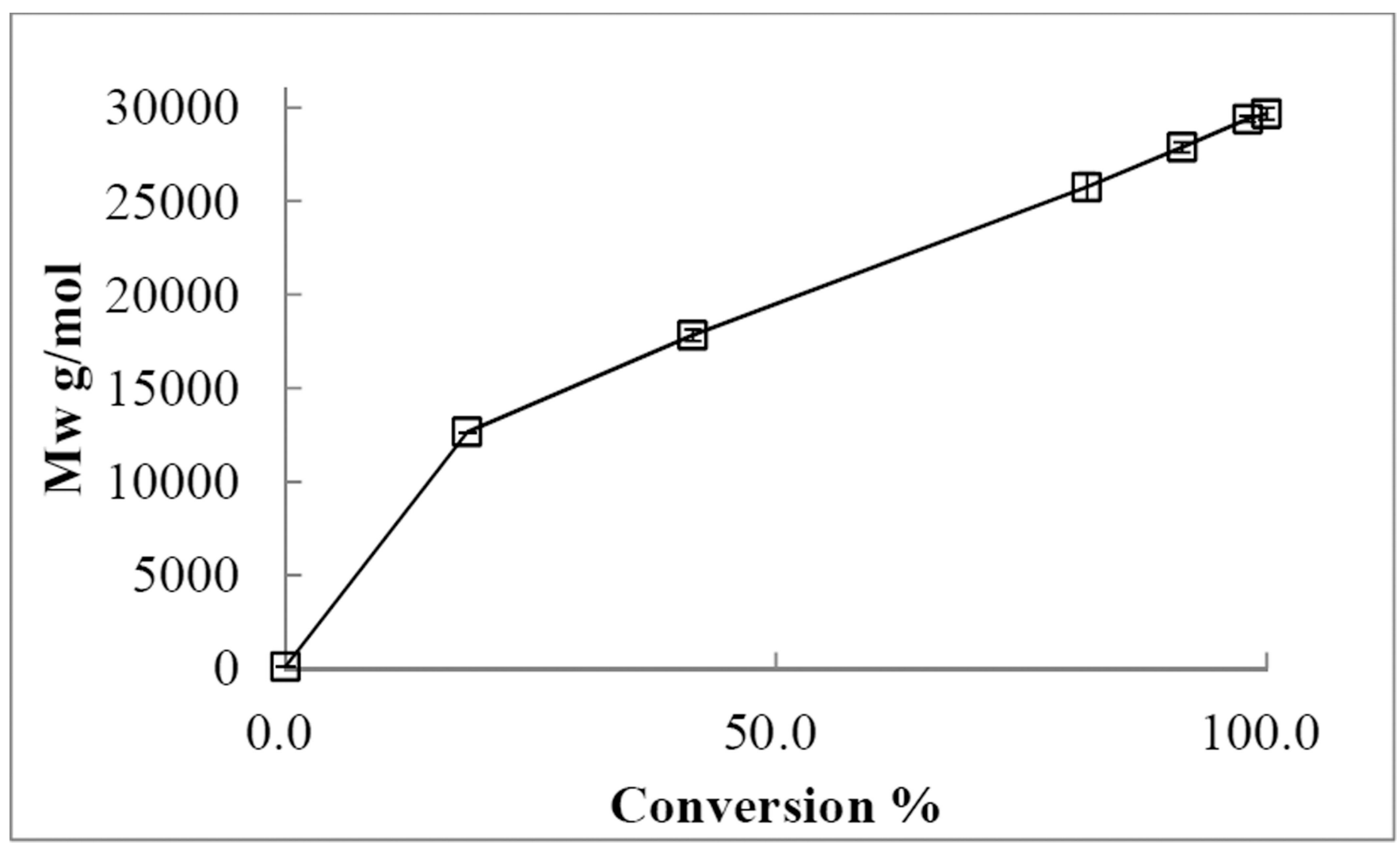

Figure 7.

Mw-conversion plot of polymerization of COD by ROMP under the experimental conditions. 


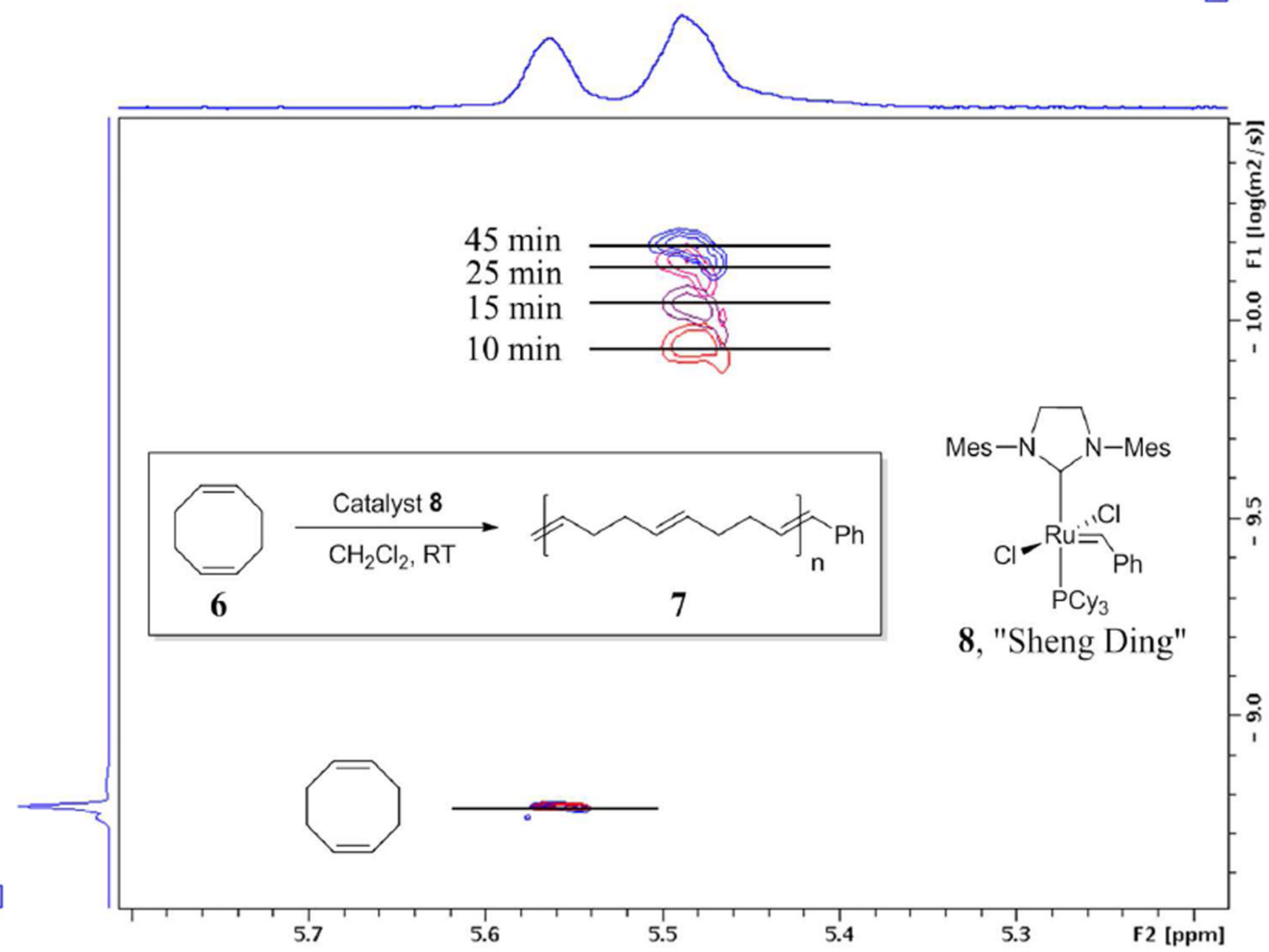

Figure 8.

Stacked DOSY spectra of the reaction crude of ROMP. DOSY spectra of 0 min, 10 min, 15 $\mathrm{min}$, and $25 \mathrm{~min}$, and $45 \mathrm{~min}$ were stacked. Olefinic peaks of cyclooctadiene were used as internal references to monitor the viscosity change of the dilute crude solution. 


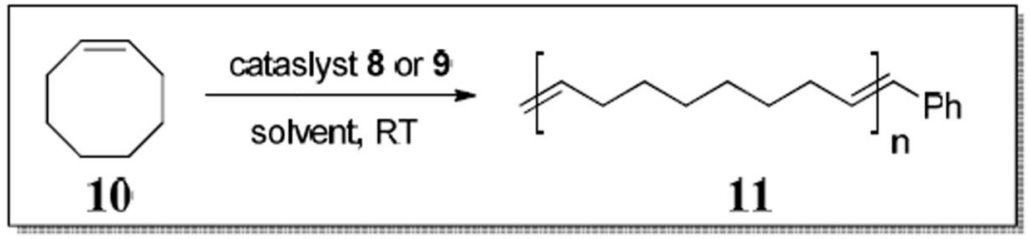

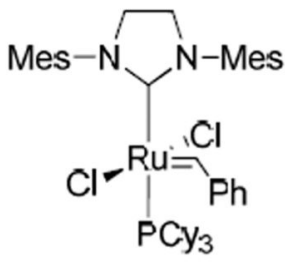

8

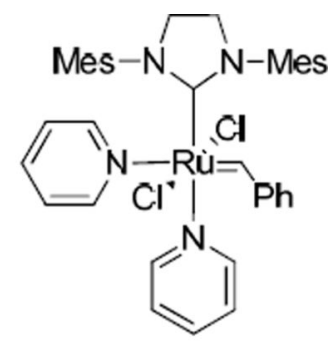

9

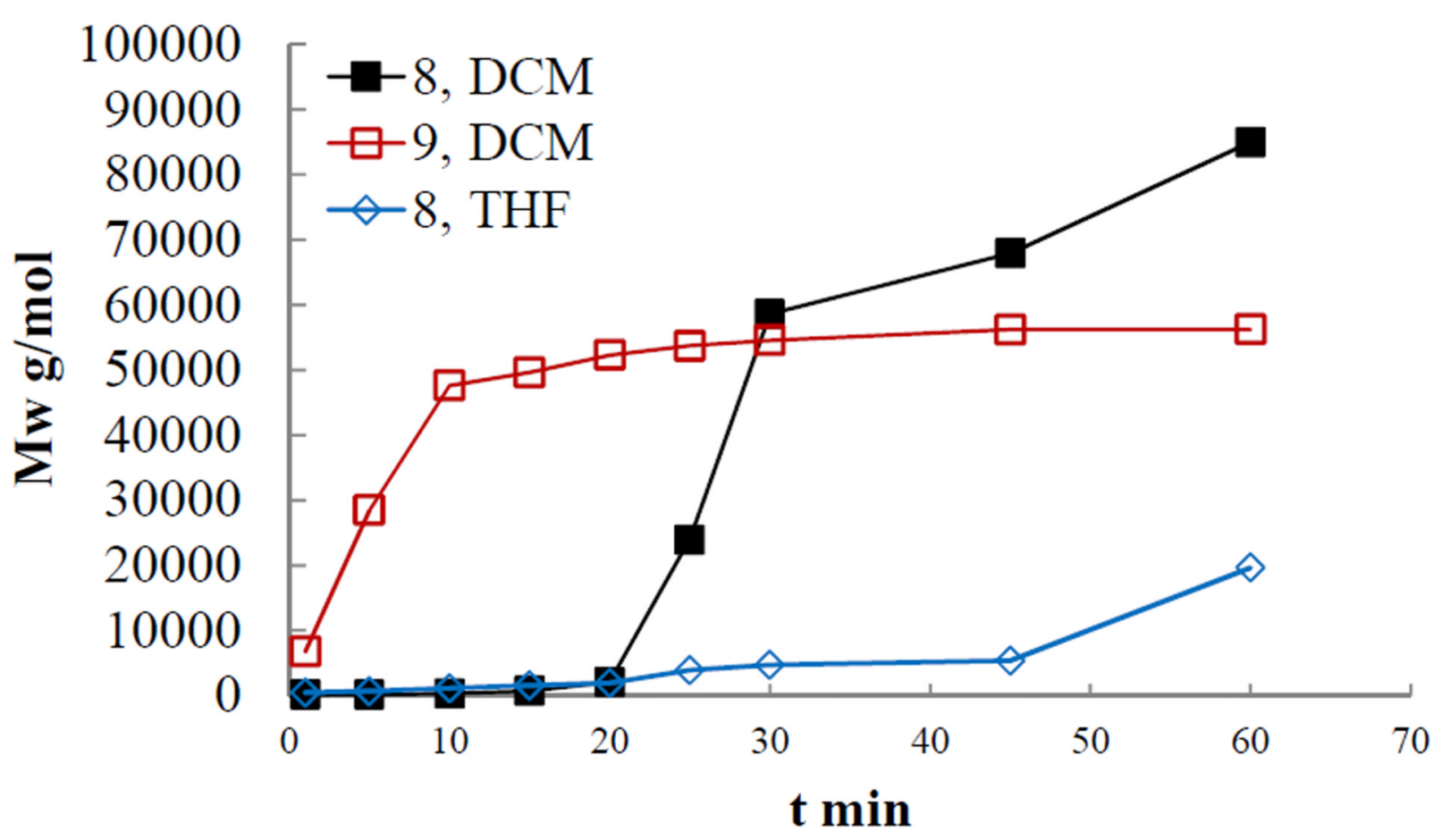

Figure 9.

Mw-t plot of polymerization of cyclooctene by ROMP. The monomer to catalyst ratio is $5000 / 1$. All reactions were performed in dry dichloromethane or THF at room temperature in $0.5 \mathrm{M}$ concentration. 

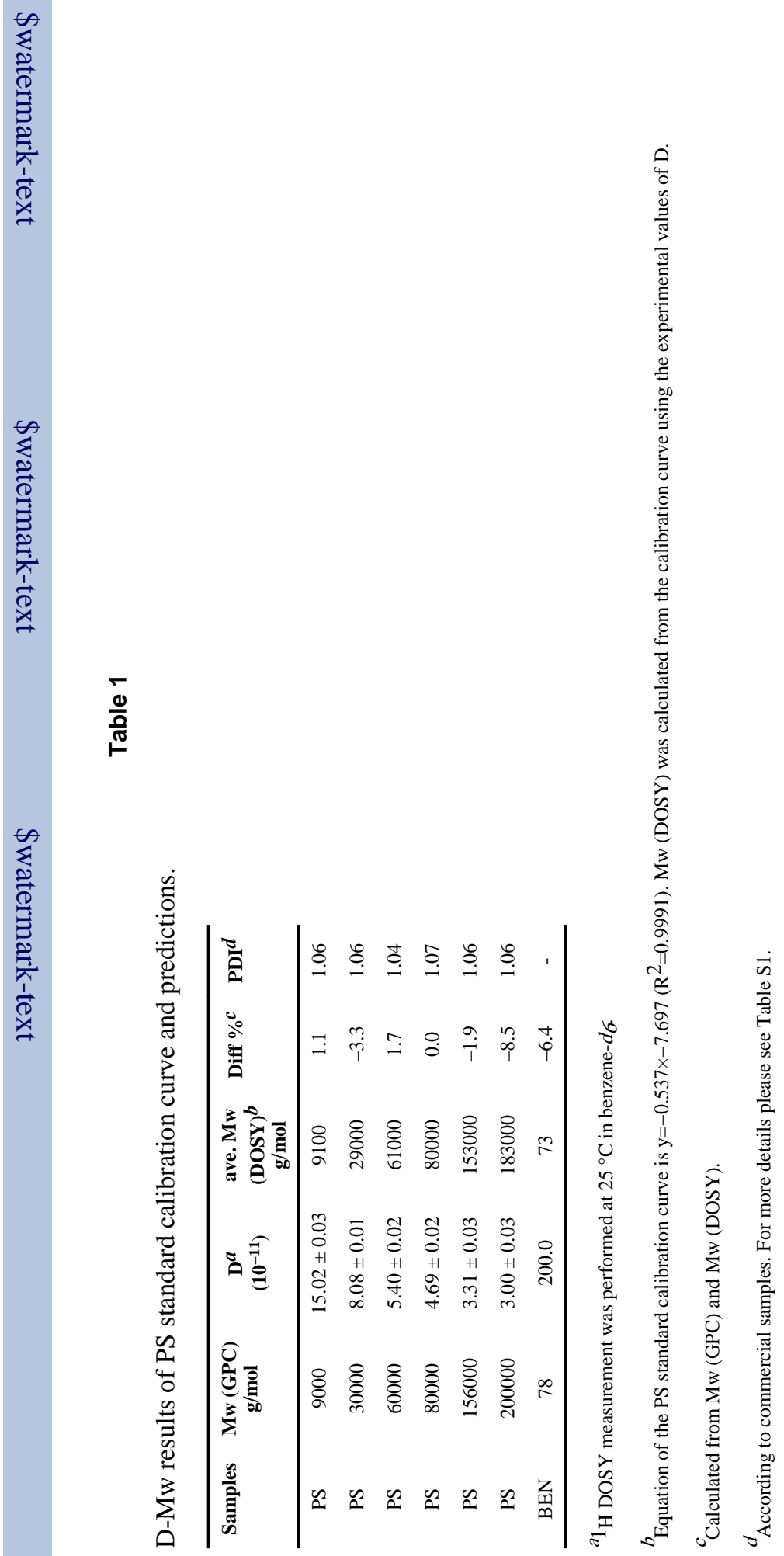

Macromolecules. Author manuscript; available in PMC 2013 December 21. 


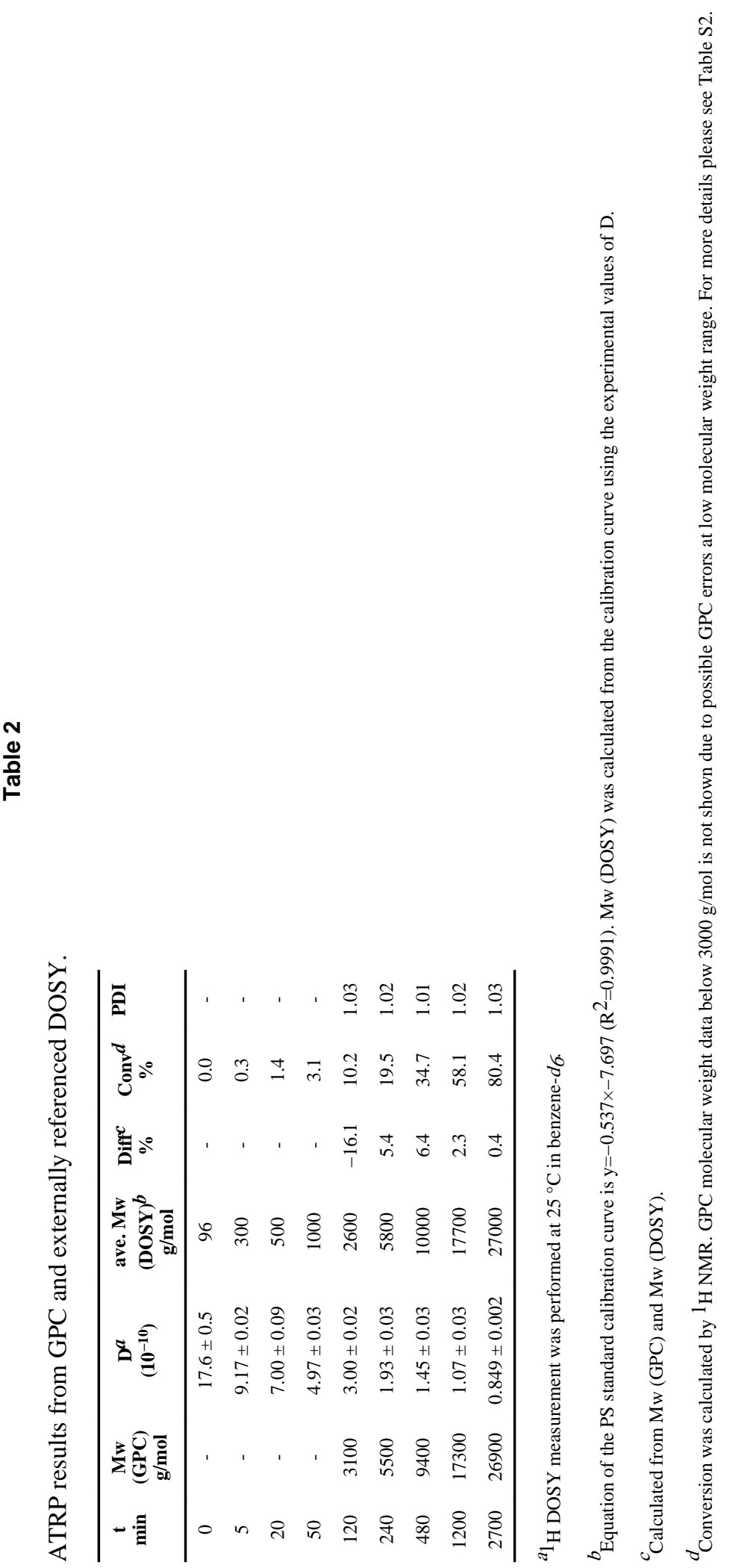




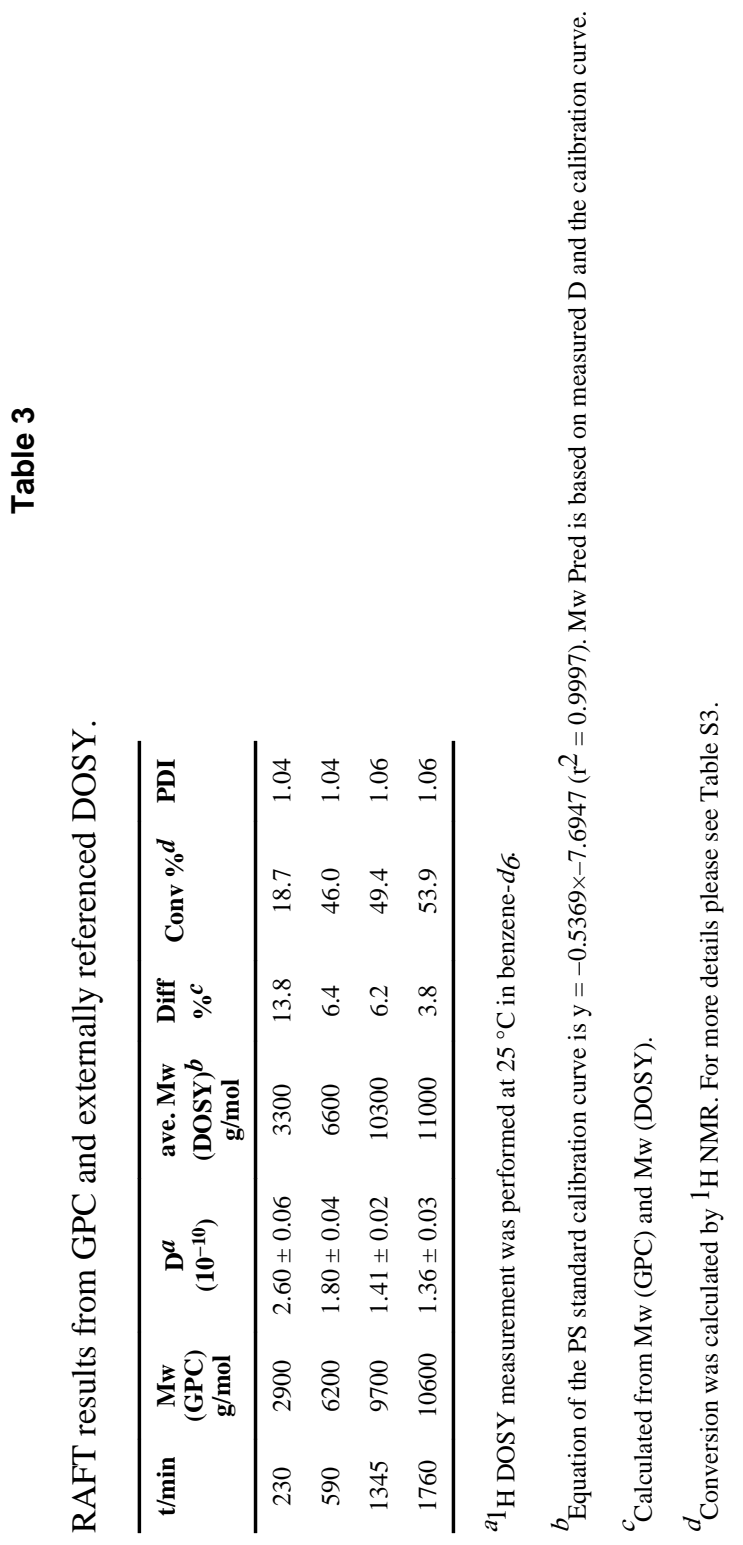

Macromolecules. Author manuscript; available in PMC 2013 December 21. 